\title{
Nutritional status of elderly residents of long-term care homes in Klang Valley, Malaysia: a cross-sectional study
}

\author{
Sook Fan Yap ${ }^{1}$, FRCPath, FRCPA, Nem Yun $\mathbf{B o o}^{2}$, MRCP, FRCPCH, Pramod \\ Divakara Shenoy ${ }^{3}$, MSc (Physiotherapy), Siew Fun Liew ${ }^{4}, \mathrm{BN}, \mathrm{MN}$, Li Fong \\ Woo $^{4}$, BN, MN, Peak Yean Choo ${ }^{4}$, BN, MN, Pooi Pooi Leong ${ }^{1}$, BSc, PhD, Nadia \\ Mohamad Hatta ${ }^{1}$, MBBS, MPhil
}

\begin{abstract}
Introduction. This study aimed to determine the nutritional status of elderly residents of long-term care homes in KlangValley, Malaysia, and to identify risk factors associated with malnutrition.
\end{abstract}

Methods: A total of 506 participants were assessed by trained healthcare personnel, using the Mini Nutritional Assessment (MNA) for the nutritional status, the Mini-Cog for the cognition status, and the Katz Index of Independence in Activities of Daily Living for the level of dependency.

Results: Of 506 participants, 200 (39.5\%) were well nourished (MNA score $\geq 24), 250(49.4 \%)$ were at risk of malnutrition (MNA score 1723.5), and $56(11.1 \%)$ were malnourished (MNA score <17). Risk factors independently associated with those malnourished or at risk of malnutrition were age $\geq 80$ years (adjusted odds ratio $[A O R]=2.04$ ), Malay ethnicity $(\mathrm{AOR}=2.91)$, no schooling $(\mathrm{AOR}=2.14)$, primary schooling $(\mathrm{AOR}=1.69)$, cognitive impairment $(\mathrm{AOR}=3.06)$, Katz score of 2-3 $(\mathrm{AOR}=2.86)$, and Katz score of $0-1(\mathrm{AOR}=16.87)$. Those who were divorced $(\mathrm{AOR}=0.34)$ or widowed $(\mathrm{AOR}=0.44)$ had significantly lower risk than those who were married. Sex and number of comorbidities were not risk factors.

Conclusion: Among residents of long-term care homes in KlangValley, those aged $\geq 80$ years, of Malay ethnicity, with little or no schooling, with cognitive impairments, and with Katz score of $\leq 3$ were more likely to develop malnutrition.

Key words: Aged; Homes for the aged; Malnutrition; Risk factors

\section{ORIGINAL ARTICLE}

Faculty of Medicine and Health Sciences, Universiti Tunku Abdul Rahman, Kajang, Selangor, Malaysia:

1 Department of Pre-Clinical Science

2 Department of Population Medicine

3 Department of Physiotherapy

4 Department of Nursing
Correspondence to: Prof Nem-Yun Boo, Department of Population Medicine, Faculty of Medicine and Health Sciences, Universiti Tunku Abdul Rahman, Jalan Sungai Long, Bandar Sungai Long, 43000 Kajang, Selangor, Malaysia.

Email: boony@utar.edu.my

\section{INTRODUCTION}

Under-nutrition has negative impacts on health, particularly among elderly people. Ageing is associated with an increased risk of malnutrition secondary to physiological changes and comorbidities. Chronic illnesses and the associated polypharmacy have a negative impact on the nutritional status. Determining the prevalence of malnutrition and its associated risk factors in elderly people enables healthcare planners to formulate strategies. It is estimated that Malaysia will reach ageing population status by the year 2035, at which point $15 \%$ of the total population will be aged $\geq 60$ years. ${ }^{1}$ In a 2005 study based on the Nutritional Health Checklist, the prevalence of under-nutrition 
was $32.1 \%$ for moderate risk and $26.6 \%$ for high risk among elderly people in publicly funded shelter homes in Peninsular Malaysia. ${ }^{2}$ In a 2015 study based on the Mini Nutritional Assessment (MNA) Short Form, 39.1\% were at risk of malnutrition and 25.9\% were malnourished among institutionalised elderly people in northern Peninsular Malaysia. ${ }^{3}$

Klang Valley, located in the middle of Peninsular Malaysia, is the most developed and populated part of the country. Increasing number of elderly people are sent by their relatives to long-term care homes, particularly privately operated homes. This study aimed to determine the nutritional status of longterm care home elderly residents in Klang Valley, Malaysia, and to identify risk factors associated with malnutrition.

\section{METHODS}

This cross-sectional study was carried out between August 2015 and October 2017. Inclusion criteria were residents of long-term care homes in Klang Valley aged $\geq 60$ years. Of 67 homes approached (including fee-for-service and charity-based homes), 28 (41.8\%) granted permission to study their 712 residents. Of them, 506 (71.1\%) fulfilled the inclusion criteria, provided written consent, and completed the assessment (Figure 1). Participants were interviewed by trained healthcare personnel to obtain social, demographic, and relevant medical information. The nutritional status was assessed using the $\mathrm{MNA}_{,}{ }^{4}$ the cognitive status was assessed using the Mini-Cog test, ${ }^{5}$ and the functional status (level of dependency) was assessed using the Katz Index of Independence in Activities of Daily Living (ADL). ${ }^{6}$

The MNA has been validated in healthy, frail, and acutely ill subjects, ${ }^{7}$ as well as in a longitudinal survey. ${ }^{8}$ The MNA involves a two-step process. The first step is a brief screen comprising questions on food intake, weight loss, mobility, psychological stress or acute illness, presence of dementia or depression, and body mass index (BMI). In those identified in the first step as malnourished or at risk of malnutrition (MNA score $<12$ ), full assessment is carried out. After full assessment, nutritional status is categorised as well-nourished (MNA score $\geq 24$ ), at risk of malnutrition (MNA score 17-23.5), and malnourished (MNA score <17).

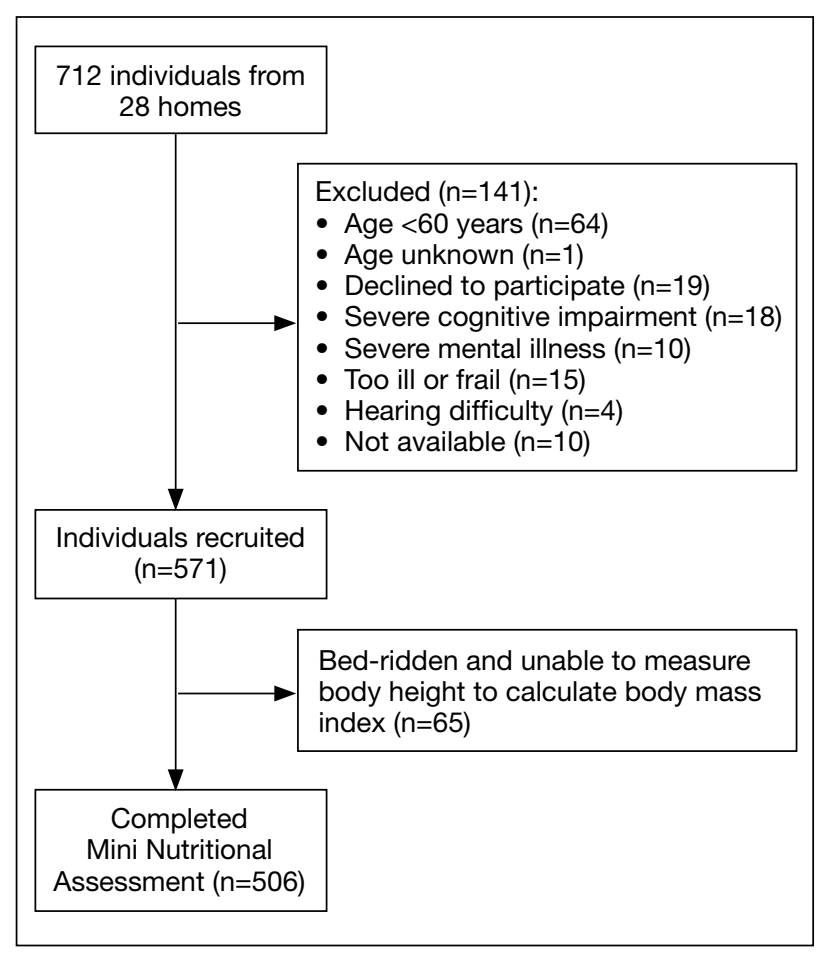

FIGURE 1. Flow diagram showing recruitment of study subjects.

The Mini-Cog test consists of a three-item recall test for memory and a simple clock drawing test. Briefly, the subject is given three words to be recalled after the clock drawing test that acts as a distracter. The subject is considered negative for cognitive impairment if all three words are recalled or if one or two words are recalled and the clock drawing test is normal. The subject is considered positive for cognitive impairment if no word is recalled or if the clock drawing test is abnormal.

The Katz Index includes five ADL: transferring, toileting, bathing, dressing, and feeding. For each of the five ADL, a score of 1 was assigned for independence and a score of 0 for dependence. A total score of 5 indicates the individual can perform all five ADL independently.

Data were analysed using SPSS (Windows version 24; IBM Corp, Armonk [NY], US). Continuous variables were presented as mean \pm standard deviation (SD) when normally distributed and as median (range) when skewed. Categorical variables were presented as number and percentage. Univariate logistic regression analysis was carried out between well-nourished group and other 
groups of at risk of malnutrition, malnourished, and combination of two. Factors that were significant $(p<0.05)$ in univariate logistic regression analysis were included in the multivariate logistic regression analysis. A p value of $<0.05$ were considered statistically significant.

\section{RESULTS}

The mean age of the 506 participants was 74.4 (SD, 8.7; range, 60-100) years. $61.9 \%$ were women. In terms of ethnicity, $84.2 \%$ were Chinese, $4.3 \%$ were Indian, $11.3 \%$ were Malay, and $0.2 \%$ were of other ethnicity.

Of 506 participants, 200 (39.5\%) were well nourished, 250 (49.4\%) were at risk of malnutrition, and 56 (11.1\%) were malnourished. The mean age of the respective groups was $72.2 \pm 8.6$ years, $75.1 \pm 8.4$ years, and $78.7 \pm 8.4$ years. The median MNA score was 22.3 (SD, 4.0; range, 9.5-30.0).

Of 506 participants, 83 (16.6\%) were underweight $\left(<18.5 \mathrm{~kg} / \mathrm{m}^{2}\right), 181(36.2 \%)$ were normal $(18.5-$ $\left.22.9 \mathrm{~kg} / \mathrm{m}^{2}\right), 78(15.6 \%)$ were overweight (23-24.9 $\left.\mathrm{kg} / \mathrm{m}^{2}\right)$, and $158(31.6 \%)$ were obese $\left(\geq 25 \mathrm{~kg} / \mathrm{m}^{2}\right)$. The mean BMI was 23.1 (SD, 5.0; range, 10.6-46.5) $\mathrm{kg} / \mathrm{m}^{2}$. The BMI correlated with the MNA score (Pearson correlation coefficient $=0.477, \mathrm{p}<0.0001$, FIGURE 2).

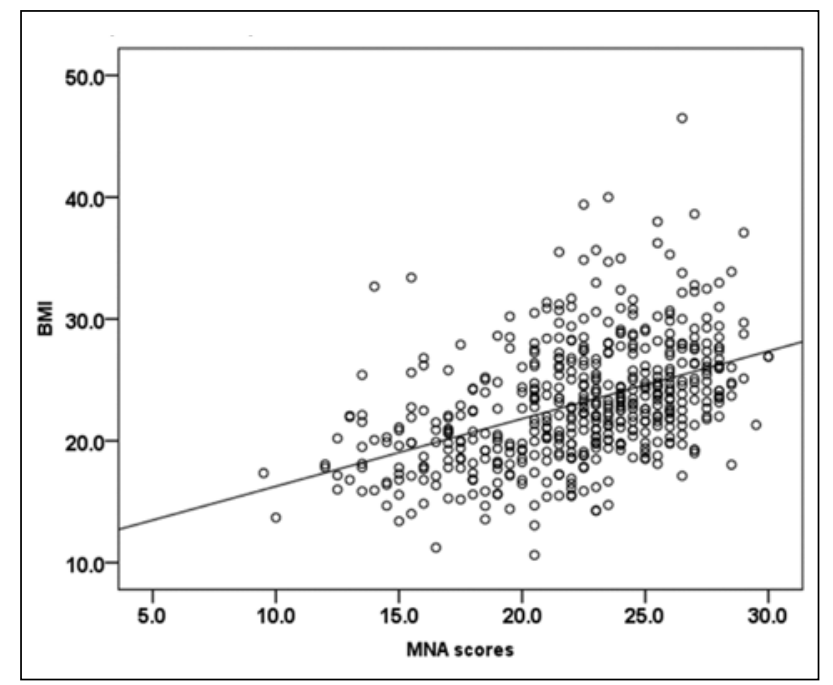

Figure 2. Body mass index (BMI) and Mini Nutritional Assessment (MNA) score of elderly residents of long-term care homes in Klang Valley, Malaysia
Compared with the well-nourished group, the at risk of malnutrition group was older $(p<0.001)$, comprised more women $(\mathrm{p}<0.05)$, and more participants with Malay ethnicity $(\mathrm{p}<0.01)$, no schooling $(\mathrm{p}<0.05)$, cognitive impairment $(\mathrm{p}<0.001)$, and Katz score of $0-1 \quad(p<0.01)$ or $2-3(p<0.05)$. In multivariate logistic regression analysis, risk factors for at risk of malnutrition were age $\geq 80$ years, Malay ethnicity, presence of cognitive impairment, and Katz score of 0-1 (TABLE). Being widowed or divorced were associated with lower risk $(\mathrm{p}<0.05)$. Sex, number of comorbidities, and schooling were not risk factors.

Compared with the well-nourished group, the malnourished group was older ( $\mathrm{p}<0.001)$, comprised more women $(\mathrm{p}<0.01)$, and more participants with no schooling $(\mathrm{p}<0.01)$, cognitive impairment $(\mathrm{p}<0.001)$, and Katz score of $0-1(p<0.001)$ or $2-3(p<0.001)$. In multivariate logistic regression analysis, risk factors for malnutrition were age $\geq 80$ years, no schooling or primary schooling, presence of cognitive impairment, and Katz score of $\leq 3$ (TABLE). Being widowed was associated with lower risk of malnutrition $(\mathrm{p}<0.05)$. Sex, ethnicity, and number of comorbidities were not risk factors.

Risk factors independently associated with those malnourished or at risk of malnutrition were age $\geq 80$ years (adjusted odds ratio $[\mathrm{AOR}]=2.04$ ), Malay ethnicity $(\mathrm{AOR}=2.91)$, no schooling $(\mathrm{AOR}=2.14)$ or primary schooling (AOR=1.69), cognitive impairment $(\mathrm{AOR}=3.06)$, Katz score of 2-3 $(\mathrm{AOR}=2.86)$, and Katz score of $0-1(\mathrm{AOR}=16.87)$ [TABLE]. Those who were divorced $(\mathrm{AOR}=0.34)$ or widowed $(\mathrm{AOR}=0.44)$ had significantly lower risk than those who were married. Sex and number of comorbidities were not risk factors.

\section{DISCUSSION}

The MNA has been validated to have high sensitivity, specificity, and predictive value, and is accurate in identifying nutrition risk. ${ }^{7,9}$ Identifying those at risk of malnutrition is clinically relevant, as timely intervention may stop the weight loss and improve the MNA score of elderly people. ${ }^{9}$ The MNA can also be used for follow-up assessment. Unlike the BMI that detects body weight changes, the MNA assesses the protein-calorie status. 
Yap et al

TABLE

Nutritional status of elderly residents of long-term care homes in Klang Valley, Malaysia, assessed using the Mini Nutritional Assessment (MNA)

\begin{tabular}{|c|c|c|c|c|}
\hline \multirow[t]{2}{*}{ Variable } & MNA score $\geq 24$ & MNA score $17-23.5$ & MNA score $<17$ & MNA score $\leq 23.5$ \\
\hline & $\begin{array}{l}\text { Well nourished } \\
\qquad(\mathrm{n}=200)\end{array}$ & $\begin{array}{l}\text { At risk of malnutrition } \\
\qquad(\mathrm{n}=250)\end{array}$ & $\begin{array}{l}\text { Malnourished } \\
\quad(n=56)\end{array}$ & $\begin{array}{c}\text { At risk of malnutrition } \\
\text { or malnourished } \\
(n=306)\end{array}$ \\
\hline Median (range) MNA score & $26.0(24.0-30.0)$ & $21.5(17.0-24.5)$ & $15.0(9.5-16.5)$ & $20.5(9.5-23.5)^{\ddagger}$ \\
\hline Mean $\pm S D$ age, y & $72.5 \pm 8.6$ & $75.1 \pm 8.4^{\ddagger}$ & $78.7 \pm 8.4^{\ddagger}$ & $75.8 \pm 8.5^{\ddagger}$ \\
\hline $60-69$ & $89(44.5)$ & $75(30.0)$ & $9(16.1)$ & $84(27.5)$ \\
\hline $70-79$ & $68(34.0)$ & $90(36.0)$ & $18(32.1)$ & $108(35.3)$ \\
\hline$\geq 80$ & $43(21.5)$ & $85(34.0)$ & $29(51.8)$ & $114(37.3)$ \\
\hline \multicolumn{5}{|l|}{ Sex, no. (\%) } \\
\hline Chinese & $174(87.0)$ & $203(81.2)$ & $49(87.5)$ & $252(82.4)$ \\
\hline Indian & $12(6.0)$ & $9(3.6)$ & $1(1.8)$ & $10(3.3)$ \\
\hline Malay & $13(6.5)$ & $38(15.2)$ & $6(10.7)$ & $44(14.4)$ \\
\hline Others & $1(0.5)$ & 0 & 0 & $0(0)$. \\
\hline \multicolumn{5}{|l|}{ Marital status, no. (\%) } \\
\hline Married & $34(17.0)$ & $69(27.6)$ & $14(25.0)$ & $83(27.1)$ \\
\hline Divorced & $16(8.0)$ & $8(3.2)$ & $3(5.4)$ & $11(3.6)$ \\
\hline Single & $89(44.5)$ & $90(36.0)$ & $12(21.4)$ & $102(33.3)$ \\
\hline Widowed & $57(28.5)$ & $81(32.4)$ & 27 (48.2) & $108(35.3)$ \\
\hline Unknown & $5(2.5)$ & $9(3.6)$ & $1(1.8)$ & $10(3.3)$ \\
\hline No. of comorbidities, no. (\%) & $(n=160)$ & $(n=186)$ & $(n=36)$ & $(n=222)$ \\
\hline 0 & $28(17.5)$ & $35(18.8)$ & $7(19.4)$ & $42(18.9)$ \\
\hline $1-2$ & $106(66.3)$ & $118(63.4)$ & $20(55.6)$ & $138(62.2)$ \\
\hline$\geq 3$ & $26(16.3)$ & $33(17.7)$ & $9(25.0)$ & $42(18.9)$ \\
\hline \multicolumn{5}{|l|}{ Cognitive impairment, no. (\%) } \\
\hline No & $157(78.5)$ & $132(52.8)$ & $20(35.7)$ & $152(49.7)$ \\
\hline Yes & $38(19.0)$ & $96(38.4)$ & $30(53.6)$ & $126(41.2)$ \\
\hline Not able to test & $5(2.5)$ & $22(8.8)$ & $6(10.7)$ & $28(9.2)$ \\
\hline $\begin{array}{l}\text { Katz Index of Independence in Activities } \\
\text { of Daily Living score, no (\%) }\end{array}$ & & & $(n=55)$ & $(n=305)$ \\
\hline $4-5$ & $193(96.5)$ & 207 (82.8) & $25(45.5)$ & $232(76.1)$ \\
\hline $2-3$ & $5(2.5)$ & $19(7.6)$ & $7(12.7))$ & $26(8.5)$ \\
\hline $0-1$ & $2(1.0)$ & $24(9.6)$ & $23(41.8)$ & $47(15.4)$ \\
\hline
\end{tabular}

* $p<0.05$

$+p<0.01$

$\mp p<0.001$ 


\begin{tabular}{|c|c|c|c|c|c|}
\hline \multicolumn{2}{|c|}{ Well-nourished vs at risk of malnutrition } & \multicolumn{2}{|c|}{ Well-nourished vs malnourished } & \multicolumn{2}{|c|}{$\begin{array}{l}\text { Well-nourished vs at risk of malnutrition } \\
\text { or malnourished }\end{array}$} \\
\hline $\begin{array}{l}\text { Odds ratio } \\
(95 \% \mathrm{Cl})\end{array}$ & $\begin{array}{l}\text { Adjusted odds ratio } \\
(95 \% \mathrm{Cl})\end{array}$ & $\begin{array}{l}\text { Odds ratio } \\
(95 \% \mathrm{Cl})\end{array}$ & $\begin{array}{l}\text { Adjusted odds ratio } \\
(95 \% \mathrm{Cl})\end{array}$ & $\begin{array}{l}\text { Odds ratio } \\
(95 \% \mathrm{Cl})\end{array}$ & $\begin{array}{l}\text { Adjusted odds } \\
\text { ratio }(95 \% \mathrm{Cl})\end{array}$ \\
\hline- & - & - & - & - & - \\
\hline & - & - & - & & \\
\hline Reference & Reference & Reference & Reference & Reference & Reference \\
\hline $1.57(1.01-2.44)^{\star}$ & $1.61(0.97-2.66)$ & $2.62(1.11-6.19)^{\star}$ & $2.57(0.74-8.90)$ & $1.68(1.10-25.8)^{\star}$ & $1.63(0.10-2.67)$ \\
\hline $2.35(1.45-3.79)^{\ddagger}$ & $1.96(1.11-3.46)^{\star}$ & $6.67(2.90-15.32)^{\ddagger}$ & $4.01(1.08-15.0)^{*}$ & $2.81(1.77-4.45)^{\ddagger}$ & $2.04(1.17-3.58)^{\star}$ \\
\hline Reference & Reference & Reference & Reference & Reference & Reference \\
\hline $1.5(1.04-2.21)^{\star}$ & $1.16(0.74-1.81)$ & $3.49(1.70-7.13)^{\dagger}$ & $2.39(0.83-6.89)$ & $1.73(1.20-2.49)^{+}$ & $1.20(0.77-1.87)$ \\
\hline Reference & Reference & Reference & & Reference & Reference \\
\hline $0.64(0.27-1.56)$ & $0.80(0.29-2.23)$ & $0.30(0.04-2.33)$ & - & $0.58(0.24-1.36)$ & $0.75(0.27-2.12)$ \\
\hline $2.51(1.29-4.86)^{\dagger}$ & $2.87(1.29-6.41)^{\star}$ & $1.64(0.59-4.54)$ & - & $2.34(1.22-4.47)^{\star}$ & $2.91(1.30-6.49)^{\dagger}$ \\
\hline- & 0 & 0 & & 0 & 0 \\
\hline Reference & Reference & Reference & Reference & Reference & Reference \\
\hline $0.25(0.10-0.63)^{+}$ & $0.33(0.12-0.95)^{\star}$ & $0.46(0.11-1.81)$ & $0.80(0.13-5.13)$ & $0.28(0.12-0.67)^{\dagger}$ & $0.34(0.12-0.91)^{\star}$ \\
\hline $0.50(0.30-0.83)^{+}$ & $0.63(0.36-1.09)$ & $0.33(0.14-0.78)^{\star}$ & $0.37(0.11-1.19)$ & $0.47(0.29-0.77)^{\dagger}$ & $0.59(0.34-1.02)$ \\
\hline $0.70(0.41-1.19)$ & $0.46(0.26-0.85)^{\star}$ & $1.15(0.53-2.49)$ & $0.28(0.09-0.94)^{*}$ & $0.78(0.47-1.30)$ & $0.44(0.24-0.79)^{\dagger}$ \\
\hline $0.25(0.04-1.41)$ & $0.46(0.08-2.82)$ & 0 & 0 & $0.21(0.04-1.17)$ & $0.41(0.07-2.50)$ \\
\hline Reference & Reference & Reference & Reference & Reference & Reference \\
\hline $1.83(1.07-3.11)^{\star}$ & $1.86(0.99-3.48)$ & $3.89(1.71-8.85)^{\dagger}$ & $6.27(1.58-24.86)^{\dagger}$ & $2.11(1.26-3.51)^{\dagger}$ & $2.14(1.16-3.95)^{\star}$ \\
\hline $1.42(0.93-2.16)$ & $1.61(0.99-2.61)$ & $2.09(0.99-4.38)$ & $4.35(1.19-15.86)^{\star}$ & $1.51(1.01-2.26)^{\star}$ & $1.69(1.04-2.74)^{\star}$ \\
\hline $1.89(0.61-5.86)$ & $1.38(0.36-5.35)$ & $1.10(0.12-10.27)$ & $0.94(0.00-229.57)$ & $1.81(0.60-5.51)$ & $1.33(0.34-5.17)$ \\
\hline Reference & & Reference & & Reference & \\
\hline $0.89(0.51-1.56)$ & - & $0.76(0.29-1.96)$ & - & $0.87(0.51-1.49)$ & - \\
\hline $1.02(0.50-2.08)$ & - & $1.39(0.45-4.26)$ & - & $1.08(0.54-2.13)$ & - \\
\hline Reference & Reference & Reference & & Reference & Reference \\
\hline $3.01(1.93-4.67)^{\ddagger}$ & $2.83(1.76-4.54)^{\ddagger}$ & $6.20(3.18-12.08)^{\ddagger}$ & $5.26(2.10-13.19)^{\ddagger}$ & $3.43(2.24-5.24)^{\ddagger}$ & $3.06(1.92-4.87)^{\ddagger}$ \\
\hline $5.23(1.93-14.20)^{\dagger}$ & $5.07(1.75-14.71)^{\dagger}$ & $9.42(2.63-33.7)^{\dagger}$ & $7.68(1.05-56.37)^{\star}$ & $5.78(2.18-15.37)^{\ddagger}$ & $5.40(1.88-15.49)^{\dagger}$ \\
\hline Reference & Reference & Reference & Reference & Reference & Reference \\
\hline $3.54(1.30-9.67)^{\star}$ & $2.61(0.90-7.58)$ & $10.81(3.19-36.64)^{\ddagger}$ & $5.51(1.24-24.54)^{\star}$ & $4.33(1.63-11.48)^{\dagger}$ & $2.86(1.01-8.08)^{\star}$ \\
\hline $11.19(2.61-47.97)^{\dagger}$ & $9.31(2.04-42.46)^{\dagger}$ & $88.78(19.74-399.39)^{\ddagger}$ & $236.14(30.90-1804.71)^{\ddagger}$ & $19.55(4.49-81.52)^{\ddagger}$ & $16.87(3.88-73.37)^{\ddagger}$ \\
\hline
\end{tabular}


In the present study, based on the BMI, only $16.6 \%$ of participants were underweight and obesity was common. However, based on the MNA, > $>0 \%$ of participants were either at risk of malnutrition $(49.4 \%)$ or malnourished $(11.1 \%)$. In a review of 32 studies involving 6821 institutionalised elderly people, 51\% (standard error, $0.6 \%$; range, $27 \%$ $70 \%$ ) were at risk of malnutrition and $21 \%$ (standard error, $0.5 \%$; range, $5 \%-71 \%$ ) were malnourished. ${ }^{9} \mathrm{~A}$ study on institutionalised elderly people in northern Peninsular Malaysia found that 39.1\% were at risk of malnutrition and $25.9 \%$ were malnourished. ${ }^{3}$ In the present study, $49.4 \%$ were at risk of malnutrition and $11.1 \%$ were malnourished. A possible reason for the difference in the prevalence of malnutrition is the ethnic distribution between the study populations. Residents from northern Peninsular Malaysia are largely Malay (68.9\%), whereas our study population comprised $84.2 \%$ Chinese, and based on the results of our study, Malay ethnicity was associated with malnutrition. In addition, malnourished residents may have been excluded from our study who were bedridden ( $\mathrm{n}=65)$, too weak/frail for assessment $(n=15)$, or with severe cognitive impairment $(n=18)$. The high proportion of those at risk of malnutrition underscores the importance of early detection and intervention to revert or halt the progress.

In a study using BMI and the Nutritional Health Checklist, the proportion of underweight (BMI $<18.5$ $\mathrm{kg} / \mathrm{m}^{2}$ ) was $14.3 \%$, and the prevalence of undernutrition was $32.1 \%$ for moderate risk and $26.6 \%$ for high risk among elderly people in publicly funded shelter homes in Peninsular Malaysia. ${ }^{2}$ Higher number of comorbidities was reported to be a nutritional risk factor. However, factors such as age, ethnicity, education level, cognitive impairment, and level of independence in ADL were not investigated. In the present study, despite the relatively small number of Malay participants, Malay ethnicity was identified to be a risk factor, suggesting that cultural belief and practice in food intake may play an important role. Our study concurs with other studies that risk factors for malnutrition were age $\geq 80$ years, cognitive impairment, and low level of independence in ADL. ${ }^{9-14}$ Elderly people with cognitive impairments tend to have feeding difficulty and therefore malnutrition..$^{15}$ Low level of independence in ADL and hospitalisation were found to be associated with declining nutritional status and risk of malnutrition in a 2-year follow-up study. ${ }^{11}$ Smoking, amount of food intake, dental status, diabetes mellitus, and praying during free time have also been reported as risk factors. ${ }^{16}$

Residents who were divorced or widowed had lower risk of undernutrition. No previous study has reported on this. One possible explanation is that the divorced or widowed elderly participants in the present study were more focused on personal nutritional intake and not distracted by the needs of a partner.

Limitations of our study include not documenting the amount of food taken daily and the dental status of the residents, which have been reported to be risk factors for malnutrition. ${ }^{13,16,17}$

\section{CONCLUSION}

Among residents of long-term care homes in Klang Valley, those aged $\geq 80$ years, of Malay ethnicity, with little or no schooling, with cognitive impairments, and with Katz score of $\leq 3$ are more likely to develop malnutrition.

\section{ACKNOWLEDGEMENT}

This study was fully funded by a research grant from the Universiti Tunku Abdul Rahman, Malaysia (Project 2104-C1/001 and 2014-C1/002). We would like to thank Dr Thaw Zin for his help and all participants and operators for facilitating recruitment.

\section{DECLARATION}

The authors have no conflict of interest to disclose.

\section{REFERENCES}

1. Factsheet Malaysia Demographic Trends. National Population and Family Development Board. Available at: http://www.lppkn. gov.my/index.php?option=com_content\&view=article\&id=194:f actsheet-malaysia-demographic-trends\&catid=13:kependuduka n\&Itemid=541\&lang=en. Accessed 20 March 2017.

2. Visvanathan R, Zaiton A, Sherina MS, Muhamad YA. The nutritional status of 1081 elderly people residing in publicly funded shelter homes in Peninsular Malaysia. Eur J Clin Nutr 2005;59:318-24. Crossref

3. Enny E, Abdul M, Ruhaya H, Zulkarnain H. Oral hygiene and nutritional status among institutionalised elderly in Kedah and Kelantan, Malaysia. Mal J Nutr 2015;21:207-17.

4. Guigoz Y, Vellas B, Garry PJ. Mini Nutritional Assessment: a practical assessment tool for grading the nutritional state of elderly patients. Facts Res Gerontol 1994;4(Suppl 2):15-59.

5. Borson S, Scanlan J, Brush M, Vitaliano P, Dokmak A. The mini- 
cog: a cognitive 'vital signs' measure for dementia screening in multi-lingual elderly. Int J Geriatr Psychiatry 2000;15:10217. Crossref

6. Katz S, Ford AB, Moskowitz RW, Jackson BA, Jaffe MW. Studies of illness in the aged. the index of ADL: a standardized measure of biological and psychosocial function. JAMA 1963;185:9149. Crossref

7. Vellas B, GuigozY, Baumgartner M, Garry PJ, Lauque S, Albarede JL. Relationships between nutritional markers and the mininutritional assessment in 155 older persons. J Am Geriatr Soc 2000;48:1300-9. Crossref

8. The New Mexico aging process study (1979-2003). A longitudinal study of nutrition, health and aging. J Nutr Health Aging 2007;11:125-30.

9. Guigoz Y. The Mini Nutritional Assessment (MNA) review of the literature--What does it tell us? J Nutr Health Aging 2006;10:46687.

10. Chang CC, Robert BL. Malnutrition and feeding difficulty in Taiwanese older with dementia. J Clin Nurs 2011;20:215361. Crossref

11. Izawa S, Enoki H, Hasegawa J, Hirose T, Kuzuya M. Factors associated with deterioration of mini nutritional assessment- short form status of nursing home residents during a 2-year period. J Nutr Health Aging 2014;18:372-7. Crossref

12. Verbrugghe M, Beeckman D, Van Hecke A, Vanderwee K, Van Herck K, Clays E, et al. Malnutrition and associated factors in nursing home residents: a cross-sectional, multi-centre study. Clin Nutr 2013;32:438-43

13. Kulnik D, Elmadfa I. Assessment of the nutritional situation of elderly nursing home residents in Vienna. Ann Nutr Metab 2008;52(Suppl 1):51-3. Crossref

14. Pauly L, Stehle P,Volkert D. Nutrition situation of elderly nursing home residents. Z Gerontol Geriat 2007;40:3-12. Crossref

15. Chang CC. Prevalence and factors associated with feeding difficulty in institutionalized elderly with dementia in Taiwan. J Nutr Health Aging 2012;16:258-61. Crossref

16. Nazemi L, Skoog I, Karisson I, Hosseini S, Mohammadi MR, Hosseini $\mathrm{M}$, et al. Malnutrition, prevalence and relation to some risk factors among elderly residents of nursing homes in Tehran, Iran. Iran J Public Health 2015;44:218-27.

17. Kikutani T, Yoshida M, Enoki H,YamashitaY, Akifusa S, Shimazaki $Y$, et al. Relationship between nutrition status and dental occlusion in community-dwelling frail elderly people. Geriatr Gerontol Int 2013;13:50-4. Crossref 